\title{
Assessing the Peach Fruit Refractometric Index at Harvest with a Simple Model Based on Fruit Growth
}

\author{
Isabelle Grechi \\ INRA, Unité Plantes et Systèmes de culture Horticoles UR 1115, Domaine St. Paul, Site Agroparc, \\ Avignon Cedex 9, 84914 France \\ Nadine Hilgert \\ INRA, Unité Analyse des Systèmes et Biométrie, UMR 729, 2 place Viala, Montpellier Cedex 1, \\ 34060 France \\ Michel Génard and Françoise Lescourret ${ }^{1}$ \\ INRA, Unité Plantes et Systèmes de culture Horticoles UR 1115, Domaine St. Paul, site Agroparc, \\ Avignon Cedex 9, 84914 France
}

\begin{abstract}
AdDitional INDEX wORDs. Prunus persica, quality, sugar content, prediction, uncertainty, prediction intervals
Abstract. Whereas quality is an increasingly important aspect of peach fruit [Prunus persica (L.) Batsch] production at this time, it is still not adequately addressed in crop models. Our objective was to develop a model to assess an essential trait of peach fruit quality (the refractometric index at harvest) to include it in existing crop models and to address the issue of quality in programs dealing with the improvement of crop management. The model predicts the fruit refractometric index, an indicator of sugar content (the most decisive parameter in consumer satisfaction) commonly used by the fruit industry. The model was simple enough so that it could be easily linked to carbon-based crop models. It was calibrated and tested using several independent data sets representing many growing conditions. To account for the effect of uncertainty in input and model parameters, the output of the model was qualified by a prediction interval. Results indicated that the model accurately predicted refractometric indices under $12 \%$ (relative root mean squared error values of 0.09 and 0.12 for two data sets), which corresponds to the fruit industry's range of interest. Prediction intervals revealed that the uncertainty in model parameters has moderate effects, whereas the uncertainty of the model input has important effects.
\end{abstract}

Recently, fruit quality has become an increasingly important aspect of fruit production. For example, in Europe, current European Union regulations and norms for the fruit and vegetable sector have raised quality levels [Direction générale de la concurrence, de la consommation et de la répression des fraudes (DGCCRF), 2002; Interprofession de la filière des Fruits et Légumes Frais (INTERFEL), 2002; Pascale, 1992; United Nations Economic Commission for Europe (UNECE), 2006]. Therefore, research efforts directed toward improved control of fruit quality and its variability are needed. Crop models are powerful tools for such research efforts (Boote et al., 1996; Lentz, 1998). However, despite a few exceptions, quality is seldom addressed in horticultural crop models (Gary et al., 1998). Correcting this problem requires selecting a pertinent indicator of quality that well represents the perception of quality by the fruit industry and which is easy to link to ecophysiological processes already included in crop models.

In the last decade, consumer expectations regarding fruit quality have increasingly focused on gustatory quality (Jongen, 2000). Although fruit gustatory quality is a complex multicriterion concept, sugar content remains one of the most

Received for publication 15 Aug. 2007. Accepted for publication 15 Jan. 2008. This work was partially funded by grants from INRA's national ANR program "ECosphère COntinentale," Action Thématique ECOlogie pour la Gestion des Ecosystèmes et de leurs Ressources.

We gratefully acknowledge Arnaud Chapelet for his assistance in the field experiments. We also thank Alistair Hall and Gail Wagman for correcting the English.

${ }^{1}$ Corresponding author. E-mail: francoise.lescourret@avignon.inra.fr. decisive parameters in consumer satisfaction (Hilaire et al., 2000; Vaysse et al., 2000). To take quality into consideration in crop models, the refractometric index is preferable to sugar content to which it is well correlated (Hilaire et al., 2000; Véret, 2000) because it is generally used to define standard requirements for peach grades and interprofessional agreements (DGCCRF, 2002).

The aim of this study was to develop a simple model (i.e., one with few parameters) easily linked to crop models and able to predict the refractometric index of peach fruit at harvest under a wide range of growing conditions. This model was partly based on the model of Quilot et al. (2004), which describes the variation of total sugar content in peach flesh within a breeding population. Input variables were limited to the initial total sugars in the flesh, to the kinetics of fruit flesh dry weight that is a common output of crop models (precisely, to the growth rates resulting from these kinetics), and to the flesh fresh weight at harvest. The description of metabolic processes was revised.

Because there is generally uncertainty in the values of both the input variables (observed or predicted) and the parameters used in models, there is also a related uncertainty in model output. Therefore, the uncertainty of the prediction must also be quantified to use the model correctly. The first approach we applied, which is largely used by crop modelers, was sensitivity analysis. This approach consists of analyzing the effect of varying inputs or parameters to identify those to which the model is most sensitive. A second approach, which is rarely encountered, was to qualify the model output with a prediction 
interval depending on the data variability. It consists of building an interval of plausible values at a specified probability level. In this study, the calculation of prediction intervals for simulated refractometric indices, which explicitly took the true uncertainty in inputs and parameters into account, allowed us to quantify how each of these two sources of uncertainty affects the quality of the model prediction.

Model DESCRIPTION. The model predicts the daily evolution of total sugar content in peach flesh during the final stage of fruit growth (stage III) until fruit harvest and the refractometric index at harvest. This last stage corresponds to a period of rapid accumulation of sucrose (Vizzotto et al., 1996), one of the main sugars in peach fruit (Esti et al., 1997; Versari et al., 2002). The model is based on the simplified form proposed by Quilot et al. (2004) of the process-based SUGAR model developed by Génard and Souty (1996) and Génard et al. (2003) that predicts the time course of total sugar content in the flesh.

The Quilot et al. (2004) model is based on a balance of carbon flow in the fruit. The amount of carbon as total sugars in the flesh [CTS (grams)] is the flow of carbon that enters the flesh through the phloem in the form of sorbitol and sucrose minus the part of carbon used as glucose and fructose substrates for respiration and for the synthesis of compounds other than sugars (e.g., starch, acids, structural carbohydrates, and proteins):

$$
\frac{\mathrm{dCTS}(\mathrm{t})}{\mathrm{dt}}=\frac{\mathrm{dC}_{\mathrm{ph}}(\mathrm{t})}{\mathrm{dt}}-\mathrm{k}(\mathrm{t}) \operatorname{CTS}(\mathrm{t})-\frac{\mathrm{dC}_{\mathrm{r}}(\mathrm{t})}{\mathrm{dt}}
$$

where $t$ is the time expressed in days after full bloom (DAB), $\mathrm{dC}_{\mathrm{ph}} / \mathrm{dt}$ and $\mathrm{dC}_{\mathrm{r}} / \mathrm{dt}$ are the phloem and respiration flows of carbon $\left(\mathrm{g} \cdot \mathrm{d}^{-1}\right)$ into and out of the fruit, respectively, and $\mathrm{k}$ is the relative rate of transformation of carbon as sugars in the fruit flesh for the synthesis of compounds other than sugars (genotype-dependent parameter, $\mathrm{g} \cdot \mathrm{g}^{-1} \cdot \mathrm{d}^{-1}$ ).

It is assumed that the phloem flow of carbon is partitioned between flesh growth in terms of dry matter and respiration:

$$
\frac{\mathrm{dC}_{\mathrm{ph}}(\mathrm{t})}{\mathrm{dt}}=\mathrm{CC}_{\text {flesh }} \frac{\mathrm{dDW}(\mathrm{t})}{\mathrm{dt}}+\frac{\mathrm{dC}_{\mathrm{r}}(\mathrm{t})}{\mathrm{dt}}
$$

where $\mathrm{dDW} / \mathrm{dt}$ is the growth rate of the flesh dry weight $\left(\mathrm{g} \cdot \mathrm{d}^{-1}\right)$ and $\mathrm{CC}_{\text {flesh }}$ is the carbon content of the dry flesh $\left(\mathrm{g} \cdot \mathrm{g}^{-1}\right) . \mathrm{CC}_{\text {flesh }}$ is assumed to be constant throughout stage III of fruit growth (Génard and Souty, 1996). The following differential equation (Eq. [1]) can then be deduced:

$$
\frac{\mathrm{dCTS}(\mathrm{t})}{\mathrm{dt}}=\mathrm{CC}_{\text {flesh }} \frac{\mathrm{dDW}(\mathrm{t})}{\mathrm{dt}}-\mathrm{k}(\mathrm{t}) \operatorname{CTS}(\mathrm{t})
$$

where $\operatorname{CTS}\left(\mathrm{t}^{\mathrm{ini}}\right)=\mathrm{CTS}^{\mathrm{ini}}$ (grams) is the initial value.

Whereas Quilot et al. (2004) considered k to be independent of environmental factors and constant during fruit development, it should probably change with time because metabolic processes vary with the fruit development stage in peach (Moriguchi et al., 1990). Génard et al. (2003) showed that the relative rate of synthesis of compounds other than sugars from fructose and glucose was dependent on relative flesh growth rate and that the relative rate of sucrose transformation to glucose and fructose was mainly dependent on days after bloom. In the same way, the initial value of carbon as total sugars in the fruit [CTS ${ }^{\text {ini }}$ (grams)] considered constant among fruit could depend on the initial dry weight of the flesh $\left[\mathrm{DW}^{\text {ini }}\right.$ (grams)]. The possible effects of development, flesh growth rate, and temperature on the variation of $\mathrm{k}$ and the relationship between $\mathrm{CTS}^{\text {ini }}$ and DW ${ }^{\text {ini }}$ were investigated (see "Results").

At harvest, the total sugar content of the flesh fresh matter, $\mathrm{TS}\left(\mathrm{g} \cdot \mathrm{g}^{-1} \times 10^{-2}\right)$, is calculated as:

$$
\operatorname{TS}\left(\mathrm{t}_{\mathrm{h}}\right)=100 \frac{\mathrm{CTS}\left(\mathrm{t}_{\mathrm{h}}\right)}{\mathrm{CC}_{\text {sugar }}\left(\mathrm{t}_{\mathrm{h}}\right) \mathrm{FW}\left(\mathrm{t}_{\mathrm{h}}\right)}
$$

where $t_{h}$ is $\mathrm{DAB}$ at harvest, $\mathrm{FW}$ is the flesh fresh weight (grams), and $\mathrm{CC}_{\text {sugar }}$ is the mean carbon content of the sugars $\left(\mathrm{g} \cdot \mathrm{g}^{-1}\right)$.

The refractometric index at harvest [RI (\%)] was related to total sugar content at harvest by an empirical relationship (see "Results").

Finally, model inputs consist of initial flesh dry weight, daily growth rates of dry flesh weight that can be predicted by a crop model, and flesh fresh weight at harvest. When only flesh dry weight is predicted by the associated crop model, it can be used to assess flesh fresh weight by means of an empirical relationship as proposed by Léchaudel et al. (2002) on mango fruit (Mangifera indica L.):

$$
\mathrm{FW}\left(\mathrm{t}_{\mathrm{h}}\right)=\mathrm{DW}\left(\mathrm{t}_{\mathrm{h}}\right)+\mathrm{a}_{11} \mathrm{DW}\left(\mathrm{t}_{\mathrm{h}}\right)^{\mathrm{a}_{12}}
$$

where FW and DW are the flesh fresh and dry weights (grams).

The complete model, Eq. [1] to [3], plus equations explaining $\mathrm{k}(\mathrm{t}), \mathrm{CTS}^{\mathrm{ini}}$, and RI, are summarized at the end of the "Results" in a table that also provides parameter estimations.

\section{Materials and Methods}

\section{Data collection}

Data were collected from eight experiments performed between 1989 and 2006 in different orchards, both planted with peach trees of a late-maturing 'Suncrest' in southern France. Different leaf:fruit ratio treatments were applied, depending on year and orchard, resulting in contrasted growing conditions.

OrCHARD No. 1. Trees were planted in 1981 at Institut National de la Recherche Agronomique (INRA) in Avignon, France. They were grafted onto 'Grande-Ferrade 677' (GF.677) rootstock, goblet-trained, and received routine horticultural care. Measurements were performed in 1989, 1992, 1993, 1996, and 1997. In 1989, no treatment was applied (Génard et al., 1991). From 1992 to 1997, leaf:fruit ratio treatments were applied to fruit-bearing shoots isolated from the rest of the tree by girdling at their base. Leaf:fruit ratios were 5, 18, and 30 in 1992 (Génard et al., 1998) and 6 (LF6), 18 (LF18), and 30 (LF30) in 1993 and 1996 (Génard et al., 1998, 2003). In 1997, leaf:fruit ratio treatments of 10 (LF10) and 30 (LF30) were combined with irrigation treatments, i.e., water stressed (L) and well irrigated (H) (Génard et al., 2003).

OrChARD No. 2. The orchard was located at the INRA Gotheron Experimental Station in Valence. The trees, planted in 1983, were goblet-trained and received routine care except for half of them that were not nitrogen-fertilized (Génard et al., 1994). Measurements were performed in 1991.

ORCHARD NO. 3. Experiments were carried out in 2005 and 2006 on trees planted in 1998 at the INRA Avignon Research Center. Trees were placed under an insect-proof shelter. They were grafted onto 'GF677' and goblet-trained. Treatments comprised winter pruning, which consisted of the removal of 
$0 \%$ to $80 \%$ of 1 -year-old wood and chemical control of green peach aphids (Myzus persicae Sulzer). Half of the trees were aphid-infested, whereas the others were kept aphid-free. Fruit thinning was performed, leaving approximately one fruit per $30 \mathrm{~cm}$ of 1-year-old wood.

Cheek diameters and flesh dry and fresh weights were measured on fruit picked weekly in 1991, 1993, 1996, and 1997 and at four and seven sampling dates in 2005 and 2006 from approximately mid-May until fruit harvest. The concentration of the four sugars was measured weekly on the fruit of five to 10 sampled fruit-bearing shoots per treatment in 1993, 1996, and 1997. Refractometric index and total sugar content were measured at harvest in 1989, 1991, and 1992. In 2005 and 2006, cheek diameter was measured every 15 d on 150 (2005) and 240 (2006) tagged fruit from May until harvest. At harvest, flesh fresh and dry weights and the refractometric index of each fruit were measured. The flesh dry weight of the fruit was determined on fruit pieces dried to constant weight at $70{ }^{\circ} \mathrm{C}$. Sugars were measured using the necuproine method or highperformance liquid chromatography, depending on the experiment (Génard and Souty, 1996; Génard et al., 1991, 1994). The refractometric index was measured by means of a digital handheld refractometer (PR-101; Atago, Tokyo) on pieces of fruit flesh. The observed refractometric index of an individual fruit was the mean of measurements at three sampling locations. Daily temperature was recorded each year by the INRA meteorological station close to the experimental field.

\section{Model inputs}

Only experiments carried out in 1993, 1996, 1997, 2005, and 2006 provided both inputs and outputs of the model. In 2005 and 2006, flesh dry weights were estimated from regular cheek diameter measurements using an allometric relationship obtained from fruit picked in 1991, 1993, 1996, 1997, 2005, and 2006. Parameters were estimated with a linear least squares method on log-transformed data. A local polynomial regression fitting method was applied on measured or estimated dry weight (DW), and data were interpolated on a daily basis during the monitoring period. Flesh growth rate $(\mathrm{dDW} / \mathrm{dt})$ was calculated by differentiation of the interpolated flesh dry weights. In 2005 and 2006, input variables were calculated for each monitored fruit. In 1993, 1996, and 1997, inputs were calculated for an average fruit of each treatment $\times$ year combination.

\section{Estimation of model parameters}

Parameters $a_{11}$ and $a_{12}$ in Eq. [3] were estimated on data collected at fruit maturity for all years (except 1989 and 1992) by a nonlinear least squares method based on the GaussNewton algorithm. $\mathrm{CC}_{\text {flesh }}$ was taken from the literature (Génard et al., 1994). Definition and parameter estimation of the relationship between $\mathrm{CTS}^{\mathrm{ini}}$ and $\mathrm{DW}^{\mathrm{ini}}$ was performed on data collected between 75 and 85 DAB in 1993, 1996, and 1997. $\mathrm{CC}_{\text {sugar }}$ was calculated at harvest $\left(t_{h}\right)$ on data collected in 1993, 1996, and 1997 as the mean value of carbon content $\left(\mathrm{CC}_{\text {sugar }} \mathrm{i}\right)$ of the four sugars $(\mathrm{i}=$ glucose, fructose, sucrose, sorbitol), weighted according to the sugar contents of the flesh fresh matter $\left[\mathrm{S}_{\mathrm{i}}\left(\mathrm{g} \cdot \mathrm{g}^{-1} \times 10^{-2}\right)\right]$ :

$$
\mathrm{CC}_{\text {sugar }}\left(\mathrm{t}_{\mathrm{h}}\right)=\sum_{\mathrm{i}=1}^{4}\left(\mathrm{CC}_{\text {sugar } \mathrm{i}}\left(\mathrm{t}_{\mathrm{h}}\right) \mathrm{S}_{\mathrm{i}}\left(\mathrm{t}_{\mathrm{h}}\right)\right) / \sum_{\mathrm{i}=1}^{4} \mathrm{~S}_{\mathrm{i}}\left(\mathrm{t}_{\mathrm{h}}\right)
$$

Definition and parameter estimation of the empirical relationship between the refractometric index and TS was per- formed on data collected at maturity (more than 120 DAB) in 1989, 1991, and 1992.

The variation of the relative rate of sugar transformation, $\mathrm{k}$, was analyzed using data from the 1993, 1996, and 1997 experiments. k values were first calculated using Eq. [1] and daily CTS, $\mathrm{dCTS} / \mathrm{dt}$ (derived from data interpolation and differentiation as explained previously for $\mathrm{dDW} / \mathrm{dt}$ ), and $\mathrm{dDW} / \mathrm{dt}$ :

$$
\mathrm{k}(\mathrm{t})=\frac{1}{\operatorname{CTS}(\mathrm{t})}\left(\mathrm{CC}_{\text {flesh }} \frac{\mathrm{dDW}(\mathrm{t})}{\mathrm{dt}}-\frac{\mathrm{dCTS}}{\mathrm{dt}}\right)
$$

The values were then plotted against the considered potential explicative variables (temperature, relative growth rate of flesh dry weight, and time). Based on these observations, an equation was formulated to describe the variation of $\mathrm{k}$. Corresponding parameters were estimated by a nonlinear least squares method.

\section{Model goodness-of-fit and validation}

The relative root mean squared error (RRMSE), a common criterion used to quantify differences between simulations and measurements in the case of nonlinear models (Kobayashi and Salam, 2000; Wallach et al., 2001), was used to assess the goodness-of-fit of the model for data used to define the model parameters. RRMSE is defined as:

$$
\operatorname{RRMSE}=\sqrt{\frac{1}{\mathrm{~N}} \sum_{\mathrm{i}=1}^{\mathrm{N}}\left(\mathrm{y}_{\mathrm{i}}-\hat{\mathrm{y}}_{\mathrm{i}}\right)^{2} / \overline{\mathrm{y}}}
$$

where $\mathrm{y}_{\mathrm{i}}$ is the observed value, $\hat{y}_{i}$ the corresponding simulated value, $\mathrm{N}$ the number of observed data, and $\bar{y}=\sum_{i=1}^{N} \frac{y_{i}}{N}$ the mean of observed values. The smaller the value of RRMSE, the closer to the measurement the simulation is. Modeling efficiency (EF) was also computed:

$$
E F=1-\frac{\sum_{i=1}^{N}\left(y_{i}-\hat{y}_{i}\right)^{2}}{\sum_{i=1}^{N}\left(y_{i}-\bar{y}\right)^{2}}
$$

which shows to what extent the model does better than just predicting with the average $\bar{y}$. EF tends toward 1 as the simulation values approach the measurements, whereas $\mathrm{EF}=$ 0 when taking the average of the observed values as the simulation values: $\hat{y}_{i}=\bar{y}$.

The model was validated on data independent from those used for model building and obtained in the 2005 and 2006 experiments. A computer program written in $\mathrm{R}$ language $(\mathrm{R}$ Development Core Team, 2006) with input variables estimated from the validation database and parameters estimated with the calibration database (see previously) was used to perform model simulations. The differential equations were numerically integrated using the Euler method with a 1 day integration time step. The model predicted RI at maturity of each tagged fruit. The predictive quality of the model was evaluated by comparing model predictions with observations using graphical procedures and calculation of RRMSE and EF.

\section{Sensitivity analysis of the model and confidence intervals of prediction \\ Analyses were performed on an average fruit of all pooled treatment $\times$ year combinations from the 1993, 1996, and 1997}


experiments. This fruit was obtained by averaging the dry weight sequences and the fresh weight at harvest. The flesh dry and fresh weights and the RI of this average fruit were $19 \mathrm{~g}$, $159 \mathrm{~g}$, and $10.1 \%$, respectively, at harvest.

Among the different available methods for sensitivity analysis, we used the local approach. The method consisted of varying, one at a time, the input or parameter values of the model by $-10 \%$ and $+10 \%$ around the estimated parameter or basic input value and observing the effect of each modification on the model output (RI in this case). The effect was quantified by means of a sensitivity index (IS) defined here as:

$$
\mathrm{IS}_{\mathrm{i}}=\frac{\mathrm{y}_{\mathrm{i}}-\mathrm{y}_{\mathrm{ib}}}{\mathrm{y}_{\mathrm{ib}}} / \frac{\mathrm{x}_{\mathrm{i}}-\mathrm{x}_{\mathrm{ib}}}{\mathrm{x}_{\mathrm{ib}}}
$$

where $y_{i b}$ and $y_{i}$ are outputs corresponding to the basic input, $\mathrm{x}_{\mathrm{ib}}$, and to the basic input minus or plus a $10 \%$ variation, $\mathrm{x}_{\mathrm{i}}$, respectively. Among the two values corresponding to the $\pm 10 \%$ of the basic input, $x_{i}$ was the value that led to the highest variation in the output. A value of IS higher than one indicates that the variation of the model output is higher than the variation of the tested model parameter or input. A positive value of IS indicates that they vary in the same way. Local sensitivity analysis was applied to model parameters and to the input variable $\mathrm{FW}$ at harvest.

Sensitivity analysis aims at identifying parameters whose estimation is crucial. It is only based on the model structure and does not take the data into account. Moreover, because DW is a dynamic variable, local sensitivity analysis cannot be applied. To complete this study, we therefore decided to randomly generate samples of parameters or input values to approximate the a posteriori distribution of the output of the model and to calculate a prediction confidence interval. The principle is that of the Monte Carlo simulation method (Doucet et al., 2001).

The random samples were generated from confidence intervals of the parameter estimation procedure, thus taking the variability of the data into account. We did two simulation studies based on the whole model with Eq. [1] differentiated. We first provided a large number of dynamic sequences of DW. For that purpose, we decided to estimate the dynamic sequence Dc of the cheek diameter of an average fruit. We then computed a $90 \%$ prediction interval of the DW sequence at each date from the estimation procedure of the allometric relationship linking DW and cheek diameter (see "Model inputs" in the "Results"). We then represented uncertainty on DW by a set of growth curves comprised within the upper and lower boundaries of this prediction interval. Growth curves were generated using a logistic model of growth of the peach dry flesh defined by Génard and Souty (1996):

$$
\mathrm{DW}(\mathrm{t})=\mathrm{b}_{1}+\frac{\mathrm{b}_{2}}{1+\mathrm{e}^{\frac{\mathrm{b}_{3}\left(\mathrm{t}-\mathrm{t}^{\mathrm{nin}}-\mathrm{b}_{4}\right)}{\mathrm{b}_{2}}}}
$$

where $t$ is the time (DAB) and $t^{\text {ini }}$ is the number of days after bloom at the beginning of stage III of fruit growth $\left(t^{\text {ini }}=80\right.$ DAB). $b_{1}, b_{2}, b_{3}$, and $b_{4}$ are parameters whose values were estimated for each treatment from the 1993 experiment by Génard and Souty (1996). Each of the four parameters was sampled with a uniform distribution on the interval defined by its minimal and maximal estimated values. Several sets of parameters were generated by random sampling according to the uniform distributions with each set of parameters corresponding to an original growth curve. Only growth curves comprised within the $90 \%$ prediction interval were selected. RI was predicted for each of the 10,000 simulated growth curves using the computer program. All the RI predictions were used to approximate the a posteriori distribution of the quantity RI from which an empirical $90 \%$ prediction interval was deduced centered on the mean value of the RI predictions.

The second simulation study aimed at computing a $90 \%$ predic-

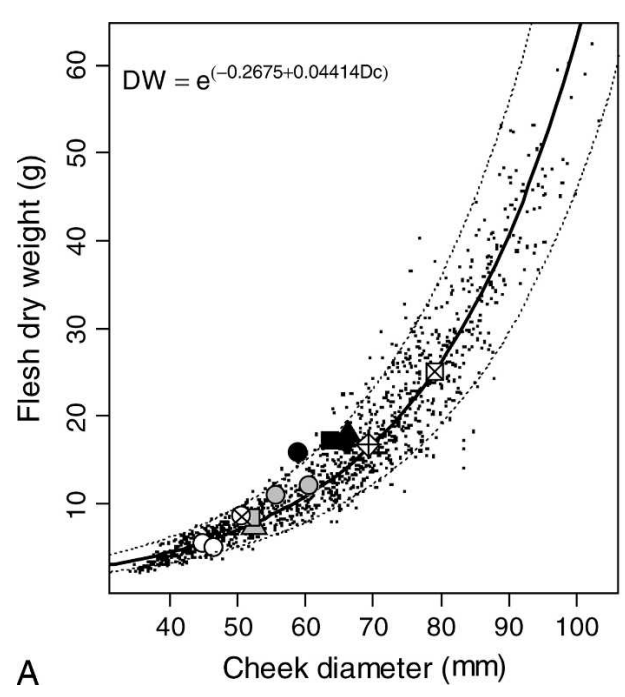

Fig. 1. Allometric relationships between (A) cheek diameter [Dc (mm)] and flesh dry weight [DW (g)], (B) flesh DW (g) and flesh fresh weight [FW (g)] of 'Suncrest' peach ("sun" in the caption) fruit sampled from $80 \mathrm{~d}$ after bloom to harvest (A) or at harvest (B). Small points represent individual fruit measurements. The 10 biggest symbols are the mean values of all the measurements of the 1991 ( $\otimes$ sun91), $2005(\diamond \operatorname{sun} 05)$, and 2006 ( $\otimes$ sun06) experiments and of each treatment in the 1993, 1996, and 1997 experiments. Treatments comprise leaf:fruit ratios of 6, 18, and 30 in 1993 and 1996 (OLF6, OLF18, •LF30) and leaf:fruit ratios of 10 and 30 combined with high $(\mathrm{H})$ and low $(\mathrm{L})$ irrigation treatments in $1997(\Delta \mathrm{LF} 10-\mathrm{H}, \mathbf{\Delta} \mathrm{LF} 30-\mathrm{H}, \mathrm{aLF} 10-\mathrm{L}, \mathbf{\square F} 30-\mathrm{L})$. Dashed lines are $90 \%$ prediction intervals.

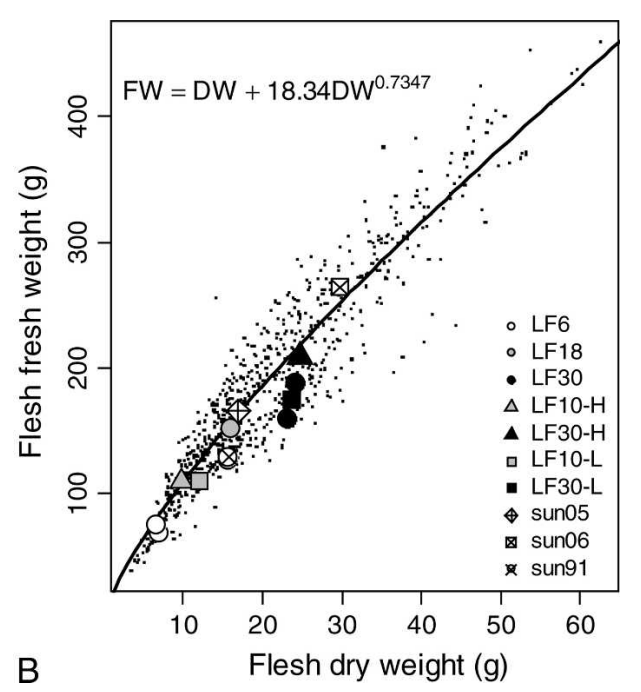

J. Amer. Soc. Hort. ScI. 133(2):178-187. 2008. tion confidence interval associated with the variability of the model parameters and a model error. Each parameter $p_{i}$ of the model was sampled with a uniform distribution on the interval defined by $\left[\hat{p}_{i} \pm t_{d f: 1-\alpha / 2} \times \hat{\sigma}_{p_{i}}\right]$, where $\hat{p}_{i}$ is the estimated value of $p_{i}$ resulting from the linear or the nonlinear least square estimation procedure, $\hat{\sigma}_{p_{i}}$ is the associated SE, and $t_{d f ; 1-\alpha / 2}$ is the quantile of the Student $t$ distribution at the 1- $\alpha$ confidence level with $\mathrm{df}$ degrees of freedom. Significance level $\alpha$ was set to 0.10 . Random samplings of each parameter according to the uniform distribution generated several sets of model parameters. Note that when two parameters, $\mathrm{p}_{1}$ and $\mathrm{p}_{2}$, were correlated, the relationship linking $\mathrm{p}_{2}$ to $\mathrm{p}_{1}$ was estimated and used to generate the random sampling of $\mathrm{p}_{2}$ from the random sampling of $\mathrm{p}_{1}$. Moreover, to consider the large variability of the 
Table 1. Final model used to predict peach fruit refractometric index at harvest: equations, corresponding parameters, unit, estimated values, and associated SE. ${ }^{\mathrm{z}}$

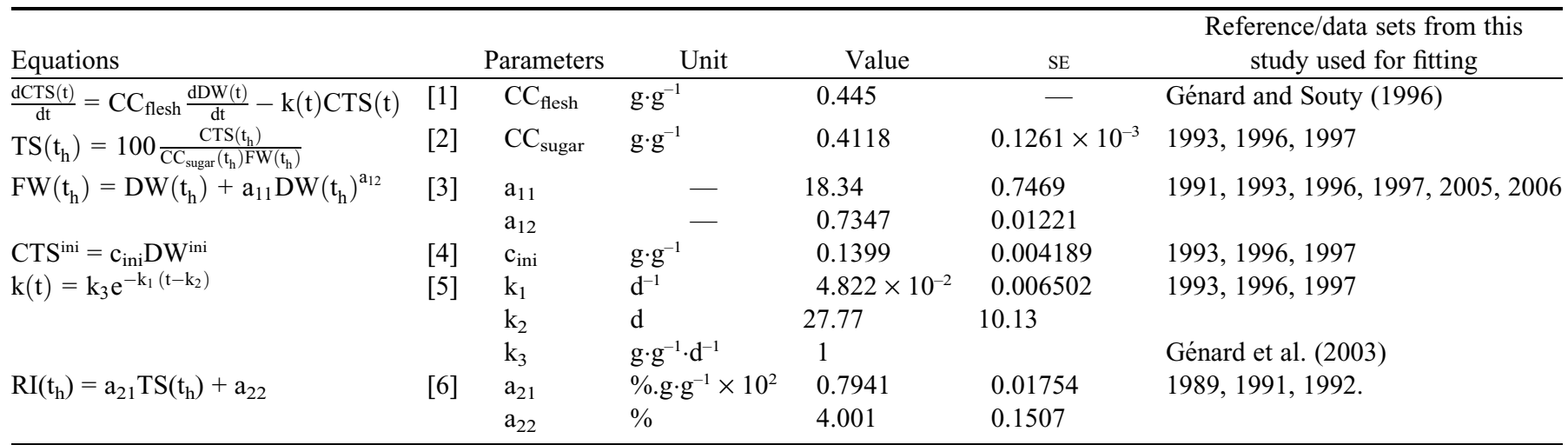

${ }^{\mathrm{z}}$ The last column indicates the reference when the parameter value was taken from the literature or the years of the corresponding experiments (see "Materials and Methods") when the parameter value was adjusted from data sets.

data when identifying parameters of $\mathrm{k}(\mathrm{t})$ in Eq. [1], we introduced a random multiplicative error before differentiation as follows:

$$
\begin{aligned}
\operatorname{CTS}(\mathrm{t}+1)= & \operatorname{CTS}(\mathrm{t})+\left(\mathrm{CC}_{\mathrm{flesh}}(\mathrm{DW}(\mathrm{t}+1)\right. \\
& -\mathrm{DW}(\mathrm{t}))-\mathrm{k}(\mathrm{t}) \operatorname{CTS}(\mathrm{t})) \varepsilon
\end{aligned}
$$

where $\varepsilon$ is a nonnegative random variable, of a mean equal to 1 , taking values between 0 and 2 . We chose to take $\varepsilon=2 \varepsilon^{\prime}$ where $\varepsilon^{\prime}$ has the distribution Beta $(4,4)$. This kind of error modeling has already been introduced for crop models (Makowski et al., 2007). An empirical $90 \%$ prediction interval of RI was computed by running the model with 10,000 sets of model parameters.

All data analyses and graphs were carried out with R software version 2.4.1 (R Development Core Team, 2006). The linear and nonlinear least squares methods used to fit models were provided by the $1 \mathrm{~m}$ and $\mathrm{nls}$ functions of $\mathrm{R}$ software, respectively. The local polynomial regression fitting method was provided by the loess function (Chambers and Hastie, 1992). the points around the fitted curve resulted not only from variability among fruit, but also from differences between treatments (Fig. 1B).

Estimation of MODEl Parameters. Parameter estimates obtained from the fitting methods are presented in Table 1. From 75 to $85 \mathrm{DAB}, \mathrm{CTS}^{\text {ini }}$ was linearly dependent on flesh dry weight $\left(r^{2}=0.95, P \leq 0.001\right)$. Thus, $\mathrm{CTS}^{\mathrm{ini}}$ can be predicted using the following equation:

$$
\mathrm{CTS}^{\text {ini }}=\mathrm{c}_{\text {ini }} \mathrm{DW}^{\text {ini }}
$$

The variation of the relative rate of sugar transformation in the fruit flesh, $\mathrm{k}$, was clearly not dependent on the mean daily temperature (Fig. 2A). At first glance, it appeared to be linearly correlated to the relative growth rate of flesh dry weight $\left(\mathrm{RGR}_{\mathrm{DW}}=\mathrm{dDW} / \mathrm{DWdt}\right.$ ) (Fig. $\left.2 \mathrm{~B}\right)$. However, if we disregard the few high values observed at the beginning of the period, the trend was not that clear. $\mathrm{k}$ was mainly dependent on days after bloom and decreased exponentially to almost 0 at harvest (Fig.

\section{Results}

Model inputs. There was a strong relationship between flesh dry weight DW and cheek diameter Dc (Fig. 1A; $r^{2}=0.93, P \leq 0.001$ ). The mean values of each treatment $X$ year combination were well distributed along the fitted curve. Only the high leaf:fruit ratio treatments (LF30) appeared to be slightly underestimated. Nevertheless, there was uncertainty in the predicted values. The $90 \%$ prediction interval for a given observation Dc ranged from approximately $\pm 32 \%$ around the predicted value of DW.

Parameter estimates of Eq. [3] relating flesh fresh weight to flesh dry weight at harvest are given in Table 1 . The RRMSE value $(0.14)$ was acceptable as was the EF value $(0.89)$. The observed dispersion of

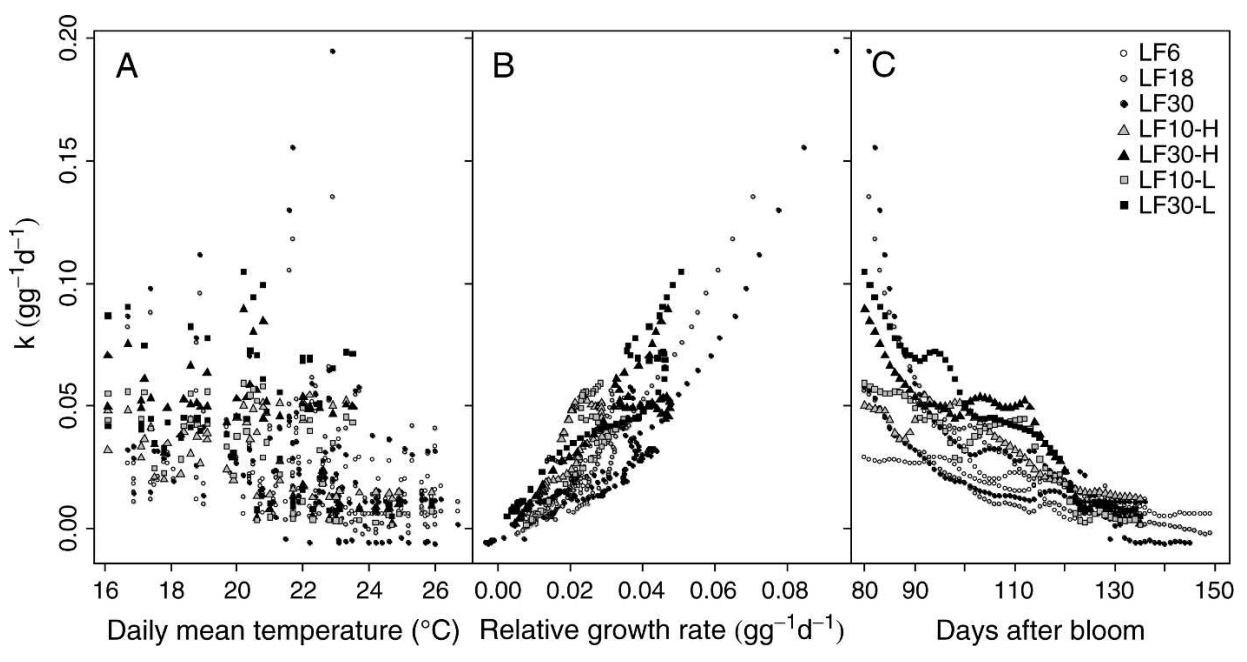

Fig. 2. Relationships between estimated relative rate of transformation of carbon as sugar in peach flesh for synthesis of compounds other than sugars $\left[\mathrm{k}\left(\mathrm{g} \cdot \mathrm{g}^{-1} \cdot \mathrm{d}^{-1}\right)\right]$ and $(\mathbf{A})$ daily mean air temperature $\left({ }^{\circ} \mathrm{C}\right),(\mathbf{B})$ relative growth rate of the dry flesh $\left(\mathrm{g} \cdot \mathrm{g}^{-1} \cdot \mathrm{d}^{-1}\right)$, and $(\mathbf{C})$ time (days after full bloom). Treatments comprise leaf:fruit ratios of 6, 18, and 30 in 1993 and 1996 (OLF6, oLF18, •LF30) and leaf:fruit ratios of 10 and 30 combined with high

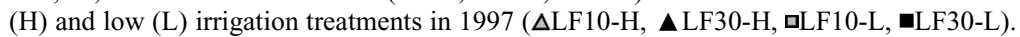


$2 \mathrm{C})$. The variations of $\mathrm{k}$ were highly affected by treatments and years up to $90 \mathrm{DAB}$. $\mathrm{k}$ appeared to be much less sensitive to growing conditions during the final stage of fruit growth than during the earlier stages. The following equation was chosen to describe the variation of $\mathrm{k}$ depending on fruit development:

$$
\mathrm{k}(\mathrm{t})=\mathrm{k}_{3} \mathrm{e}^{-\mathrm{k}_{1}\left(\mathrm{t}-\mathrm{k}_{2}\right)}
$$

where $t$ is the time (DAB) and $k_{3}$ is a constant equal to $1 \mathrm{~g} \cdot \mathrm{g}^{-1} \cdot \mathrm{d}^{-1}$. Parameters $\mathrm{k}_{1}$ and $\mathrm{k}_{2}$ were estimated based on the model resulting from the combination of Eq. [1] with Eq. [5]:

$$
\frac{\mathrm{dCTS}(\mathrm{t})}{\mathrm{dt}}=\mathrm{CC}_{\text {flesh }} \frac{\mathrm{dW}(\mathrm{t})}{\mathrm{dt}}-\mathrm{k}_{3} \mathrm{e}^{-\mathrm{k}_{1}\left(\mathrm{t}-\mathrm{k}_{2}\right)} \operatorname{CTS}(\mathrm{t})
$$

Results are given in Table 1.

The model, with the parameter values estimated previously, satisfactorily predicted the mean measured CTS (RRMSE = $0.18)$ and TS $($ RRMSE $=0.15)$ values for each treatment $\times$ year combination at harvest. We also tested the goodness-of-fit of the model with $\mathrm{k}$ considered constant over time as in the Quilot et al. (2004) model of total sugar content in peach flesh. The RRMSE values were higher ( 0.25 for TS and 0.26 for CTS), which clearly indicated that model predictions were more accurate when assuming $\mathrm{k}$ as dependent on fruit development.

Fruit harvested close to maturity (i.e., $\approx 120 \mathrm{DAB}$ ) presented a strong linear relationship $\left(r^{2}=0.83, P<0.001\right)$ between the refractometric index and the sugar content of the flesh, regardless of growing conditions (Fig. 3; Table 1):

$$
R I\left(t_{h}\right)=a_{21} T S\left(t_{h}\right)+a_{22}
$$

This confirmed that the refractometric index was a pertinent indicator to assess sugar content of fruit.

Model Validation. The model was used to predict RI of the fruit monitored in 2005 and 2006 at harvest (Fig. 4A-B). Only cheek diameters were measured sequentially. The DW values were predicted as mentioned in "Model inputs." The predictive quality of RI was acceptable for simulations performed in 2005 $(\mathrm{RRMSE}=0.14, \mathrm{EF}=0.45)$ and $2006(\mathrm{RRMSE}=0.15, \mathrm{EF}=$ 0.43 ). The relative root mean squared errors calculated on each fruit ranged from $3.7 \times 10^{-4}$ to 0.40 in 2005 and from $8.7 \times 10^{-4}$ to 0.41 in 2006 . However, for both years, the model tended to overestimate the low values and to underestimate the high values. This trend was mainly explained by an error introduced when estimating the input variable DW from diameters. This estimation error was evaluated by comparing the observed DW at harvest with the predicted one. The DW at harvest for fruit with underor overestimated RI was under- or overestimated, respectively, by the relationship presented in Figure 1A. It was suspected that earlier dry weights had been similarly misestimated. Fruit were therefore split into three groups: fruit with a correct estimation of DW at harvest (underor overestimation of less than $10 \%$ in absolute value; Group a) and fruit with an over- (more than $+10 \%$;
Group b) or underestimation (less than $-10 \%$; Group c). To improve the estimation of DW, two additional relationships (Fig. 5A) were established on fruit belonging to Groups $\mathrm{b}$ and $\mathrm{c}$. With the relationship presented in Figure 1A, RRMSE calculated from observed and estimated DW in 2005 and 2006 was

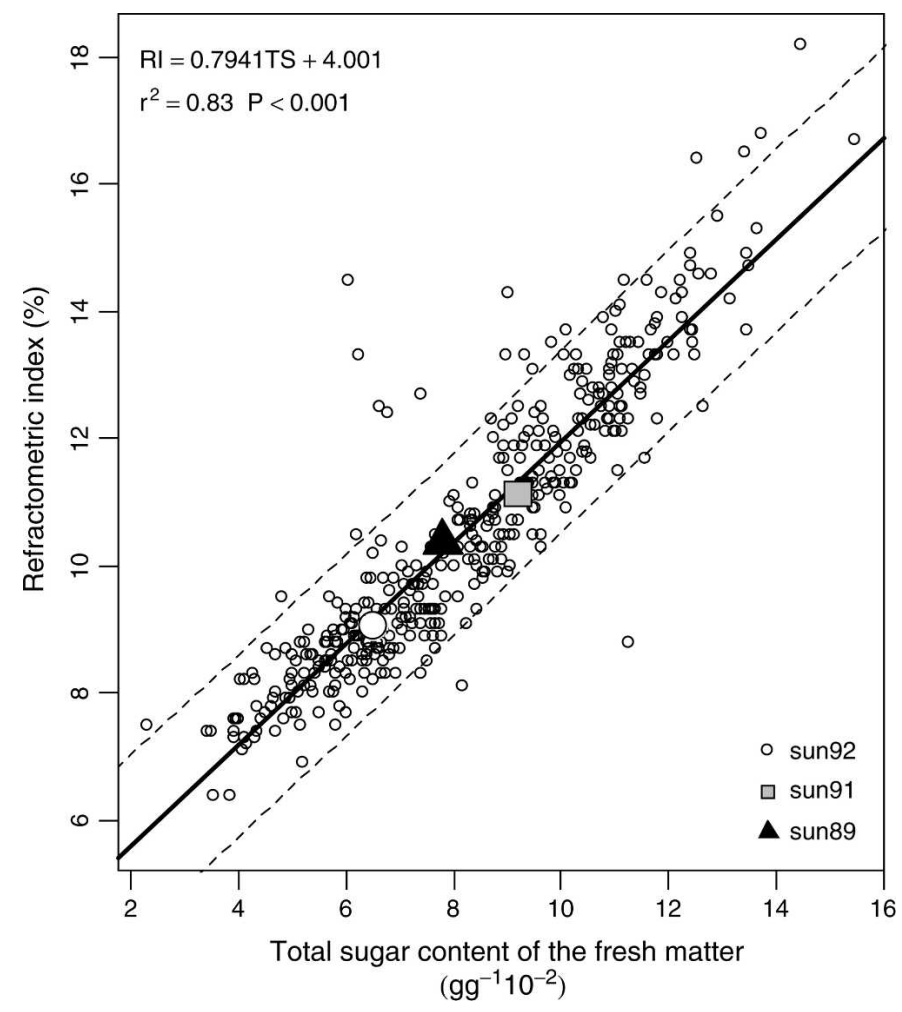

Fig. 3. Empirical relationship between total sugar content of the fresh matter of peach flesh $\left[\mathrm{TS}\left(\mathrm{g} \cdot \mathrm{g}^{-1} \times 10^{-2}\right)\right]$ and the refractometric index $(\%)$ established on "Suncrest' peach ("sun" in the legend) fruit sampled at harvest. Small points represent individual fruit measurements. The three biggest symbols are the mean values of all the measurements of the 1989 ( $\boldsymbol{\Delta}$ sun89), 1991 ( $\square$ sun91), and 1992 ( $\mathrm{o}$ sun92) experiments (see "Materials and Methods"). Dashed lines are $90 \%$ prediction intervals.

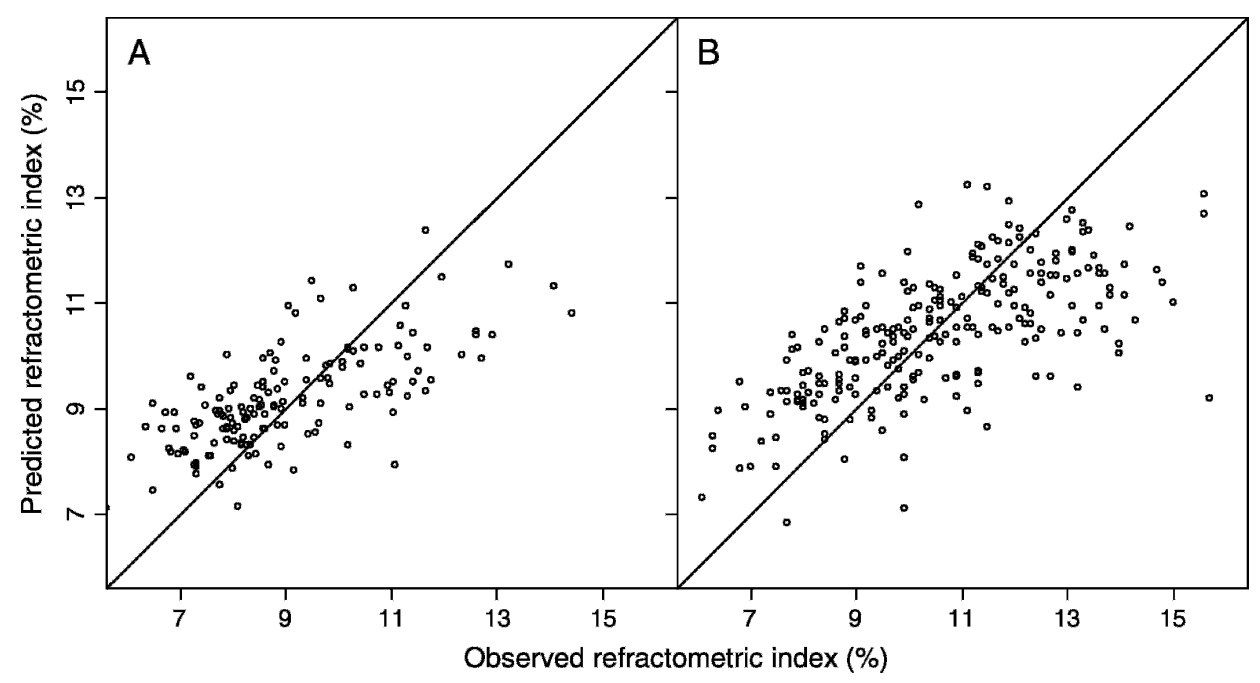

Fig. 4. Predicted versus observed peach fruit refractometric index (\%) in (A) 2005 and (B) 2006. The 1:1 line is shown. 


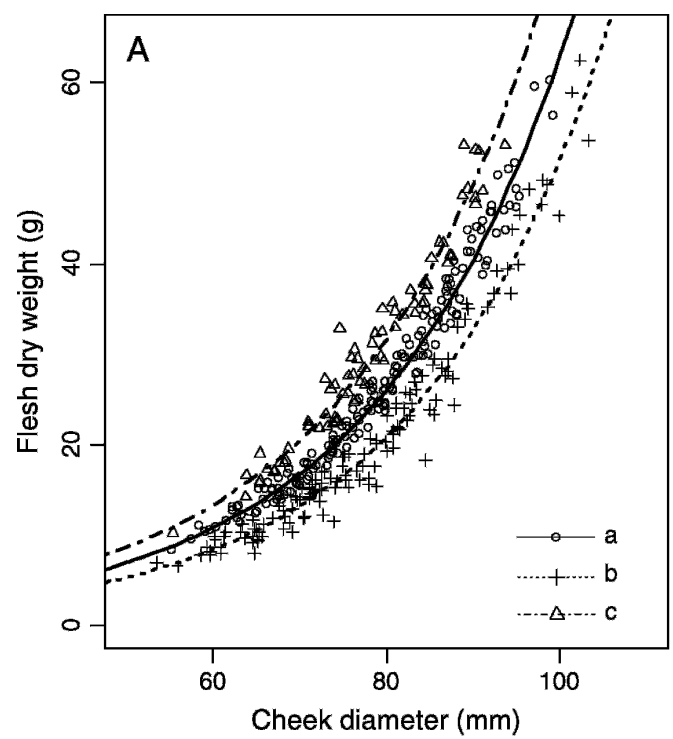

Sensitivity anAlysis of The MODEL AND CONFIDENCE INTERVALS OF PREDICTION. Model output RI was not sensitive to $\mathrm{c}_{\text {ini }}(\mathrm{IS}=0.01$ ). It was poorly sensitive to $\mathrm{k}_{2}(\mathrm{IS}=-0.26)$ and $\mathrm{a}_{22}(\mathrm{IS}=0.40)$ and slightly sensitive to $\mathrm{CC}_{\text {flesh }}$ (IS $=0.59$ ) and $\mathrm{a}_{21}$ (IS = $0.60)$. The model was more sensitive to $\mathrm{CC}_{\text {sugar }}$ (IS $=-0.67$ ) and $\mathrm{k}_{1}$ (IS = 0.82 ). The model input FW at harvest affected RI similarly to $\mathrm{CC}_{\text {sugar }}$ (IS = -0.67). A complementary analysis with a wider variation of input or parameter values indicated that the sensitivity of the model was not linearly dependent on the variation of $\mathrm{CC}_{\text {sugar }}, \mathrm{FW}, \mathrm{k}_{1}$, and $\mathrm{k}_{2}$ and linearly dependent for the other parameters (data not shown).

The method used to represent

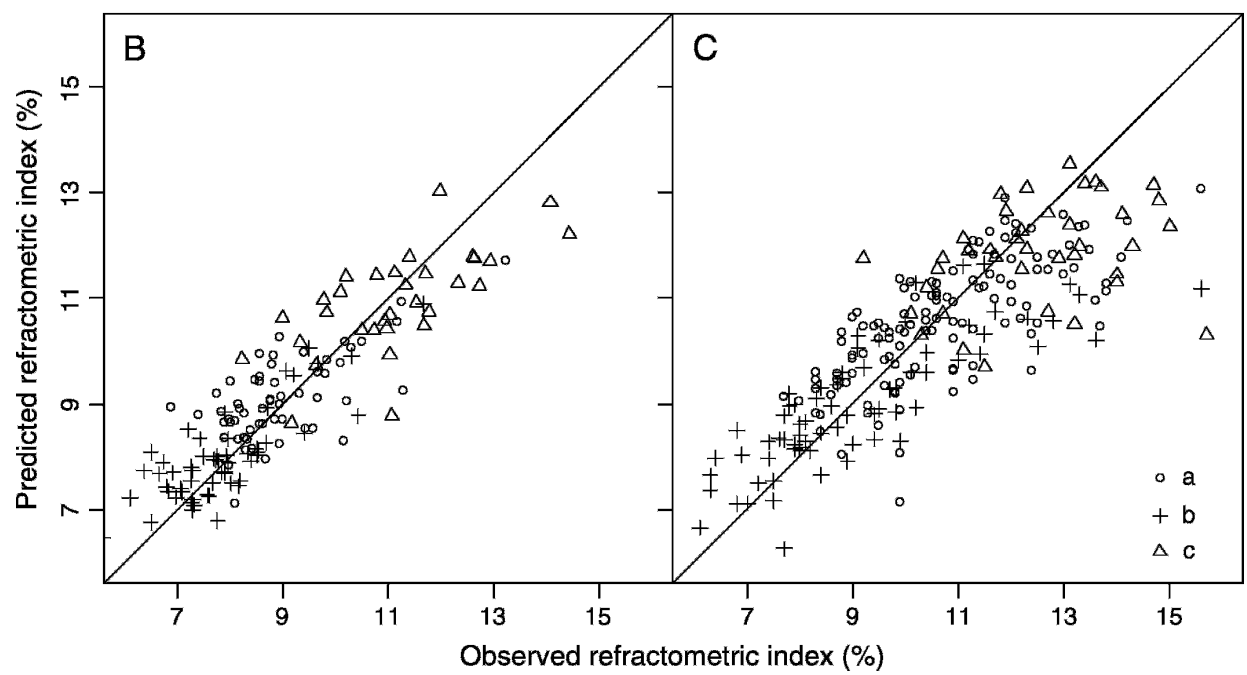

Fig. 5. Predicted versus observed peach fruit refractometric index (\%) in (B) 2005 and (C) 2006 with (A) adjusted allometric relationships between flesh dry weight [DW $(\mathrm{g})]$ and cheek diameter $[\mathrm{Dc}(\mathrm{mm})]$ of fruit at harvest. The 1:1 line is shown. Group a (O): $\mid$ observed DW - estimated DW $\mid \leq 10 \% \times$ estimated DW when using the relationship of Figure 1A to estimate DW Group b $(+)$ : (observed DW - estimated DW) $\leq-10 \% \times$ estimated DW Group c $(\Delta)$ : (observed DW - estimated DW) $\geq 10 \% \times$ estimated DW. DW of fruit belonging to Group a were estimated with the relationship of Figure 1A. DW of fruit belonging to Groups $\mathrm{b}$ and $\mathrm{c}$ were estimated with the corresponding adjusted relationships $\mathrm{b}$ and $\mathrm{c} . \mathrm{b}$ : $\mathrm{DW}=\mathrm{e}^{(-0.591+0.0454 \times \mathrm{Dc})}, r^{2}=0.96, P<0.001 \mathrm{c}$ : $\mathrm{DW}=$ $\mathrm{e}^{(-0.0130+0.0434 \times \mathrm{Dc})}, r^{2}=0.96, P<0.001$.

0.18 and $\mathrm{EF}$ was 0.86 . When using the two additional relationships, RRMSE decreased to 0.08 and EF increased to 0.97 , which is very satisfactory. Using the three relationships to estimate DW, model predictions of RI were better with RRMSE values of 0.09 in 2005 and 0.12 in 2006 and EF values of 0.5 and 0.47 , respectively. For both years, RI values were nearly distributed along the 1:1 line (Fig. $5 \mathrm{~B}-\mathrm{C}$ ). The relative root mean squared errors calculated on each fruit ranged from $7.2 \times$ $10^{-4}$ to 0.29 in 2005 and from $2.2 \times 10^{-4}$ to 0.34 in 2006 . Calculation of the coefficient of variation [Cv (\%)] of the refractometric index according to the three locations revealed a high variability within the fruit $(\mathrm{CV}=7 \%$ in 2005 and $5 \%$ in 2006). The variability of the observed output could partially explain prediction errors. A limitation of the model, observed only when testing it on data from the 2006 experiment, is its failure to predict values greater than $13 \%$. uncertainty in the model input DW allowed the generation of curves with different growth patterns. Examples of such contrasting growth curves are presented in Figure 6A. The effect of uncertainty in DW on the model output RI is presented in Figure 6B. The values of DW used for the simulations were between $\approx-27 \%$ and $+37 \%$ on average (along the time course of growth) of the reference value (average fruit) of DW. As previously observed during the validation procedure, the model appeared to be very sensitive to the input variable DW. Predicted values of RI varied between $7.8 \%$ and $13.3 \%$ with a mean of $10.5 \%$, a SD of $1.3 \%$ and a $\mathrm{CV}$ of $11.9 \%$. The empirical $90 \%$ prediction interval of the average fruit ranged from $8.5 \%$ to $12.5 \%$.

A confidence interval of prediction associated with the variability of model parameters is presented in Figure 7. Parameters of the model were generated as described in the "Materials and Methods." Parameters $\mathrm{k}_{1}$ and $\mathrm{k}_{2}$ are closely correlated and $\mathrm{k}_{2}$ can then be expressed as a linear function of $\mathrm{k}_{1}\left(r^{2}=0.84, P<0.001\right)$ :

$$
\mathrm{k}_{2}=-30.70(\mathrm{se}=10.61)+1207(\mathrm{se}=201.0) \times \mathrm{k}_{1}
$$

The same is true for parameters $\mathrm{a}_{21}$ and $\mathrm{a}_{22}$, which are linked through the relationship $\left(r^{2}=0.87, P<0.001\right)$ :

$$
\mathrm{a}_{21}=1.16(\mathrm{se}=0.06)-0.92(\mathrm{se}=0.015) \times \mathrm{a}_{22}
$$

For a given value of $k_{1}$, a value of $k_{2}$ was randomly sampled from its $90 \%$ confidence interval of prediction defined as $\left[\hat{k}_{2} \pm t_{d f ; 1-\alpha / 2} \times \hat{\sigma}_{k_{2}}\right]$, in which $\hat{k}_{2}$ is the predicted value of $\mathrm{k}_{2}$ for the given value $\mathrm{k}_{1}$ using Eq. [7], $\hat{\sigma}_{k_{2}}$ is the SD of the predicted value and $t_{d f ; 1-\alpha / 2}$ is the quantile of the Student $t$ distribution at 

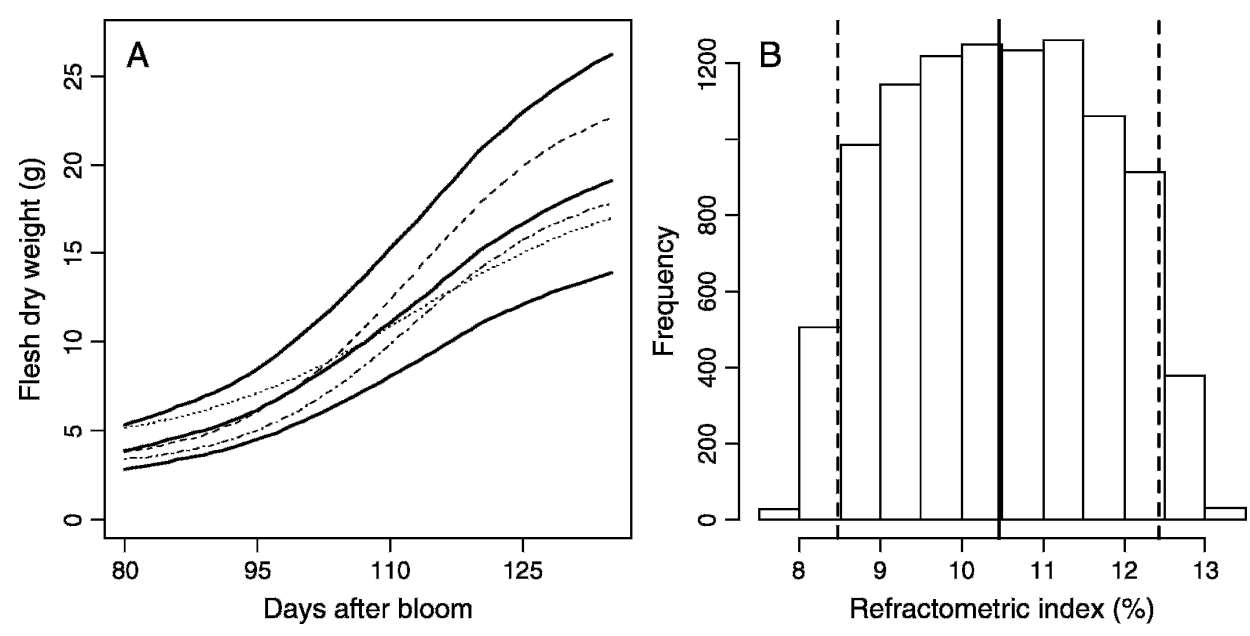

Fig. 6. (A) Prediction of growth curves of the peach flesh dry weight [DW (g)] of an average fruit of all treatment $\times$ year combinations of data collected in 1993, 1996, and 1997 (see "Materials and Methods") with upper and lower boundaries corresponding to a $90 \%$ prediction interval of DW (bold lines). Dashed lines are three examples of simulated growth curves of the dry flesh. (B) Histogram of the 10,000 simulated values of the refractometric index (\%) associated with growth curves of the peach dry flesh comprised within the $90 \%$ prediction interval of DW. Dashed lines are the limits of the $90 \%$ confidence interval of prediction and the bold line is the mean value.

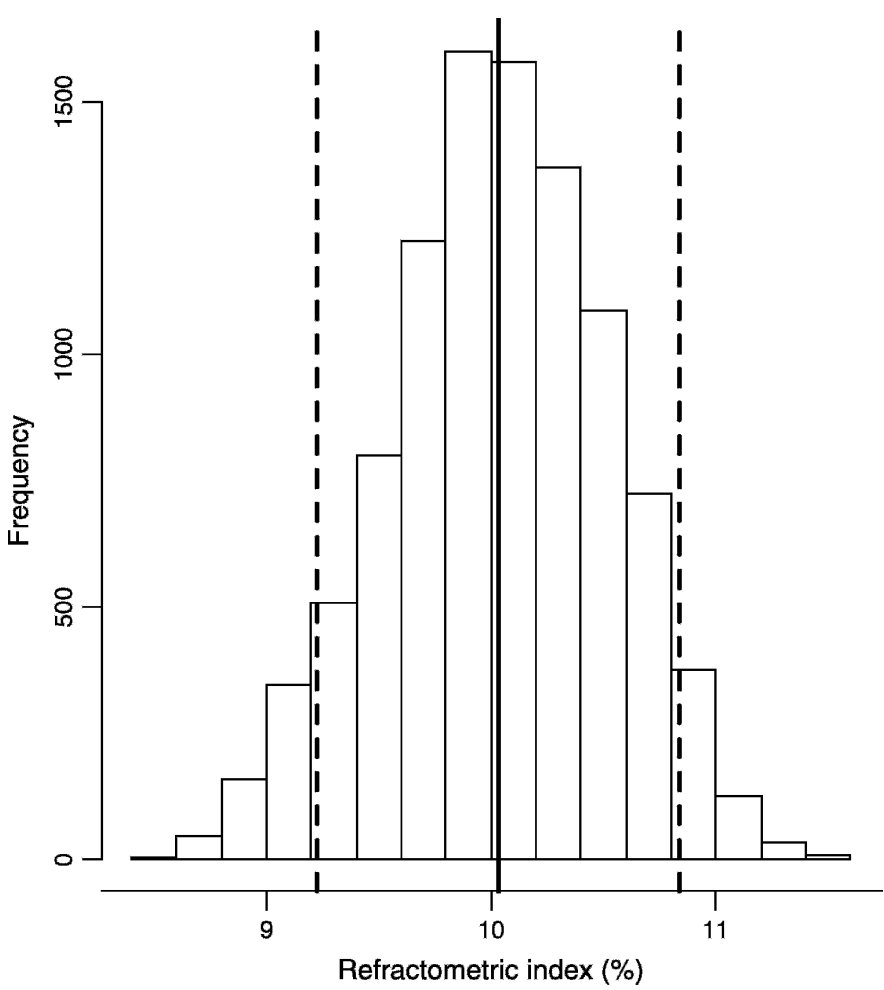

Fig. 7. Histogram of the 10,000 simulated values of the peach fruit refractometric index (\%) associated with 10,000 sets of model parameters. Dashed lines are the limits of the $90 \%$ confidence interval of prediction and the bold line is the mean value.

the $1-\alpha$ confidence level with df of the regression model. Random values of $\mathrm{a}_{21}$ and $\mathrm{a}_{22}$ were generated in the same way. Significance level $\alpha$ was set to 0.10 . Predicted values of RI varied between $8.4 \%$ and $11.5 \%$ with a mean of $10.04 \%$, a SD of $0.5 \%$, and a CV of $5 \%$. The empirical $90 \%$ prediction interval of the average fruit ranged from $9.2 \%$ to $10.85 \%$.

\section{Discussion}

The model developed in this study allowed an accurate prediction of the refractometric index of peach fruit at harvest. Sugar content in the fruit and, in the same way, the refractometric index result from a complex chain of processes and vary according to the supply of carbohydrates, changes in fruit metabolism and dilution with water supply, and increase in fruit volume (Génard et al., 2003). These three components are controlled by environmental and management factors such as irrigation or leaf:fruit ratio (Blanco et al., 1995; Bussi et al., 2005; Marini and Sowers, 1994; Souty et al., 1999). The model took these three components into account. The influence of assimilate supply and dilution was directly introduced through the two input variables, DW and FW. Metabolic transformation of carbon as sugar into compounds other than sugars was introduced with parameter k. Fruit with a high and late maximal growth rate have a high sugar content (Génard et al., 1991), indicating an effect of fruit growth pattern on sugar accumulation in the fruit. The model accounted for this property. Because the model was driven by DW, the greater the growth, the more sugar that accumulated. In addition, because $\mathrm{k}$ decreased with time, the later the growth occurred, the less carbon that was partitioned into compounds other than sugars. The pattern of $\mathrm{k}$ improved the model's goodness-of-fit compared with the Quilot et al. (2004) model in which it was considered constant. It was also consistent with the observed accumulation of sucrose concomitantly with a decrease of sucrose-hydrolyzing enzyme activity as the fruit develops (Vizzotto et al., 1996). Nevertheless, results indicated that the metabolic activity was affected by treatment $\times$ year combinations, particularly at the beginning of the final growth stage (Fig. 2C). Kobashi et al. (2000) observed changes in sorbitol metabolism in response to irrigation. Quilot et al. (2005a) observed a large instability of $\mathrm{k}$ between years. Decomposing metabolic activities and integrating environmental factors could improve the estimate of the rate of sugar transformation into other compounds, but it would greatly increase the complexity of the model (Génard et al., 2003). Because the sensitivity analysis revealed that the model was not very sensitive to $\mathrm{k}$, the effect of environmental factors can be neglected and the simplified representation of metabolic activities can be considered satisfactory.

The model will be easy to link to carbon-based models that predict flesh dry growth, its main input (Grossman and Dejong, 1994; Lescourret et al., 1998; Lescourret and Génard, 2005). Flesh fresh weight at harvest, the other model input, can be derived from models linking carbon to water processes in the fruit (Lescourret and Génard, 2005). Alternatively, FW can be estimated from DW using an allometric relationship (Eq. [3]), which should be adapted to growing conditions to reduce the estimation error. Uncertainty is generally associated with DW and FW, to which model predictions were very sensitive, whether they resulted from model predictions or fruit measurements. To 
take this uncertainty into account, the model predicts a refractometric index at harvest with an associated confidence interval of prediction. For an average fruit with an RI of $10.1 \%$, the $90 \%$ confidence interval of prediction related to an uncertainty of $\approx 30 \%$ on DW had quite a large width, equal to $4 \%$. The CV was twice as high as the $\mathrm{CV}$ measuring the intrafruit variability of RI. Nevertheless, the variation of the input was not amplified because $90 \%$ of the predicted RI varied by less than $\pm 20 \%$ from the mean value. The effect of uncertainty in the value of the model parameters was moderate because the $90 \%$ prediction interval was less than $2 \%$ of the width. As indicated by the $\mathrm{CV}$, the variability of the predicted RI was of the same order of magnitude as that observed within individual fruit. Consequently, the variability of RI introduced by the uncertainty in model parameters can be considered as moderate, whereas accurate model inputs are necessary for RI prediction.

The model was developed and successfully tested on several data representing many growing conditions and contrasted growth patterns in the Mediterranean climate. However, a complete validation requires tests in other environments (Boote et al., 1996; Gary et al., 1998; Hester and Cacho, 2003). In addition, peaches and nectarines ( $P$. persica var. nucipersica B.) exhibit considerable genotypic variations in sugar content and in flesh growth pattern (Esti et al., 1997; Quilot et al., 2004; $\mathrm{Wu}$ et al., 2003). Among breeding populations, variation is also related to the relative importance of carbohydrate supply, metabolism, and dilution, causing changes in sugar content (Quilot et al., 2004). The parameter describing the rate of sugar transformation in the Quilot et al. (2004) model is especially involved in genotypic variations (Quilot et al., 2005b). The present model was developed and calibrated on the 'Suncrest' cultivar. It could be used with other cultivars without extensive modifications. Through DW and FW, the model takes the genetic variability in assimilate supply and dilution into account. By calibrating the genotype-dependent variable $\mathrm{k}$, the model would take the genetic variability in metabolic activities into account. In addition to $\mathrm{k}$, only a maximum of three parameters involved in the carbon content of flesh and sugars and two involved in the empirical relationship between RI and TS (Table 1), if genotype-dependent, would need to be specifically reestimated.

Finally, the validation step emphasized one limitation of the model: it tended to fail to predict values beyond $13 \%$. However, values greater than $13 \%$ can be considered as very high values (Hilaire et al., 2000; Vaysse et al., 2000). Fruit with RI of less than $8 \%$ are perceived by consumers to be of poor quality contrary to fruit with higher RI $(\approx 9.5 \%$ to $10 \%)$. Beyond $10 \%$, RI has no direct consequence on consumer satisfaction (Hilaire et al., 2000). The model accurately predicted values around or below $8 \%$ to $10 \%$, corresponding to standards for grades of peaches and interprofessional agreements (DGCCRF, 2002; INTERFEL, 2002; UNECE, 2006).

In conclusion, the model developed in this study is simple, capable of accurately predicting the refractometric index, a main peach quality trait, under various growing conditions, and it can be easily linked to carbon-based models. By incorporating it into a fruit crop model or into a model of fruit crop-pest interactions, it could therefore be a useful tool to address quality in programs dealing with the improvement of crop management. A potential application would be complex agro-ecosystem models designed within the context of Integrated Fruit Production (IFP) for which quality is an integral part of performance criteria.

\section{Literature Cited}

Blanco, A., A. Pequerul, J. Val, E. Monge, and J. Gomez Aparisi. 1995. Crop-load effects on vegetative growth, mineral nutrient concentration and leaf water potential in 'Catherine' peach. J. Hort. Sci. 70:623-629.

Boote, K.J., J.W. Jones, and N.B. Pickering. 1996. Potential uses and limitations of crop models. Agron. J. 88:704-716.

Bussi, C., F. Lescourret, M. Génard, and R. Habib. 2005. Pruning intensity and fruit load influence vegetative and fruit growth in an early-maturing peach tree (cv. Alexandra). Fruits 60:133-142.

Chambers, J.M. and T.J. Hastie. 1992. Statistical models. S. Wadsworth \& Brooks/Cole Computer Science Series, Pacific Grove, CA. Direction générale de la concurrence, de la consommation et de la répression des fraudes. 2002. Avis de mise en consultation d'un cahier des charges de certification de conformité concernant des fruits de table: Pêches, nectarines, abricots. 31 July 2007. <http:// www.minefi.gouv.fr/dgccrf/boccrf/02_02/a0020018.htm/>.

Doucet, A., N. de Freitas, and N. Gordon. 2001. Sequential Monte Carlo methods in practice. Springer-Verlag, New York.

Esti, M., M.C. Messia, F. Sinesio, A. Nicotra, L. Conte, E. LaNotte, and G. Palleschi. 1997. Quality evaluation of peaches and nectarines by electrochemical and multivariate analyses: Relationships between analytical measurements and sensory attributes. Food Chem. 60:659-666.

Gary, C., J.W. Jones, and M. Tchamitchian. 1998. Crop modelling in horticulture: State of the art. Scientia Hort. 74:3-20.

Génard, M., C. Bruchou, and M. Souty. 1991. Variability of peach (Prunus-Persica L Batsch) growth and quality, and relationships between growth and quality. Agronomie 11:829-845.

Génard, M., F. Lescourret, M. Ben Mimoun, J. Besset, and C. Bussi. 1998. A simulation model of growth at the shoot-bearing fruit level. II. Test and effect of source and sink factors in the case of peach. Eur. J. Agron. 9:189-202.

Génard, M., F. Lescourret, L. Gomez, and R. Habib. 2003. Changes in fruit sugar concentrations in response to assimilate supply, metabolism and dilution: A modeling approach applied to peach fruit (Prunus persica). Tree Physiol. 23:373-385.

Génard, M. and M. Souty. 1996. Modeling the peach sugar contents in relation to fruit growth. J. Amer. Soc. Hort. Sci. 121:11221131.

Génard, M., M. Souty, S. Holmes, M. Reich, and L. Breuils. 1994. Correlations among quality parameters of peach fruit. J. Sci. Food Agr. 66:241-245.

Grossman, Y.L. and T.M. Dejong. 1994. Peach—A simulation-model of reproductive and vegetative growth in peach-trees. Tree Physiol. 14:329-345.

Hester, S.M. and O. Cacho. 2003. Modeling apple orchard systems. Agr. Systems 77:137-154.

Hilaire, C., V. Mathieu, and D. Scandella. 2000. The sugar content of peach and nectarine-Part 2. Infos-Ctifl 162:42-45.

Interprofession de la filière des Fruits et Légumes Frais. 2002. Pêche-nectarine: Les accords interprofessionnels en vigueur pour la campagne 2003 (1/7/2003). 31 July 2007. < http://www.interfel. com/article. asp? $\mathrm{id}=430 />$.

Jongen, W.M.F. 2000. Food supply chains: From productivity toward quality, p. 3-20. In: Shewfelt, R.L. and B. Brückner (eds.). Fruit and vegetable quality. An integrated view. Technomic Publishing, Lancaster, PA.

Kobashi, K., H. Gemma, and S. Iwahori. 2000. Abscisic acid content and sugar metabolism of peaches grown under water stress. J. Amer. Soc. Hort. Sci. 125:425-428.

Kobayashi, K. and M.U. Salam. 2000. Comparing simulated and measured values using mean squared deviation and its components. Agron. J. 92:345-352.

Léchaudel, M., M. Génard, F. Lescourret, L. Urban, and M. Jannoyer. 2002. Leaf-to-fruit ratio affects water and dry-matter content of mango fruit. J. Hort. Sci. Biotechnol. 77:773-777. 
Lentz, W. 1998. Model applications in horticulture: A review. Scientia Hort. 74:151-174.

Lescourret, F., M. Ben Mimoun, and M. Génard. 1998. A simulation model of growth at the shoot-bearing fruit level. I. Description and parameterization for peach. Eur. J. Agron. 9:173-188.

Lescourret, F. and M. Génard. 2005. A virtual peach fruit model simulating changes in fruit quality during the final stage of fruit growth. Tree Physiol. 25:1303-1315.

Makowski, D., T. Doré, and H. Monod. 2007. A new method to analyse relationships between yield components with boundary lines. Agron. Sustainable Dev. 27:119-128.

Marini, R.P. and D.L. Sowers. 1994. Peach fruit weight is influenced by crop density and fruiting shoot length but not position on the shoot. J. Amer. Soc. Hort. Sci. 119:180-184.

Moriguchi, T., T. Sanada, and S. Yamaki. 1990. Seasonal fluctuations of some enzymes relating to sucrose and sorbitol metabolism in peach fruit. J. Amer. Soc. Hort. Sci. 115:278-281.

Pascale, A.M. 1992. Quality in the fruit and vegetable sector: EEC regulations and influence of quality on trade and processing. Options Meditérranennes. Serie A. Séminaires Mediterranéens 19: 89-97.

Quilot, B., M. Génard, J. Kervella, and F. Lescourret. 2004. Analysis of genotypic variation in fruit flesh total sugar content via an ecophysiological model applied to peach. Theor. Appl. Genet. 109:440-449.

Quilot, B., M. Génard, F. Lescourret, and J. Kervella. 2005b. Simulating genotypic variation of fruit quality in an advanced peach $\times$ Prunus Davidiana cross. J. Expt. Bot. 56:3071-3081.

Quilot, B., J. Kervella, M. Génard, and F. Lescourret. 2005a. Analysing the genetic control of peach fruit quality through an ecophysiological model combined with a QTL approach. J. Expt. Bot. 56:3083-3092.

R Development Core Team. 2006. R: A language and environment for statistical computing. 2 Jan. 2007. <http://www.R-project.org/>.

Souty, M., M. Génard, M. Reich, and G. Albagnac. 1999. Effect of assimilate supply on peach fruit maturation and quality. Can. J. Plant Sci. 79:259-268.

United Nations Economic Commission for Europe. 2006. Committee on trade. Working party on agricultural quality standards. Specialized section on standardization of fresh fruit and vegetables. Report on its 52nd session. 15 July 2007. <http://www.unece.org/trade/agr/ meetings/ge.01/document/2006_02.pdf/>.

Vaysse, P., C. Hilaire, M. Trillot, D. Scandella, and F. Bergougnoux. 2000. Quality index: A reference system for the sector. Infos-Ctifl 165:27-29.

Véret, C. 2000. Réfractométrie et interférométrie en analyse chimique. Doc. P500. 15 July 2007. <http://www.techniques-ingenieur.fr $>$.

Versari, A., M. Castellari, G.P. Parpinello, C. Riponi, and S. Galassi. 2002. Characterisation of peach juices obtained from cultivars Redhaven, Suncrest and Maria Marta grown in Italy. Food Chem. $76: 181-185$

Vizzotto, G., R. Pinton, Z. Varanini, and G. Costa. 1996. Sucrose accumulation in developing peach fruit. Physiol. Plant. 96:225-230.

Wallach, D., B. Goffinet, J.E. Bergez, P. Debaeke, D. Leenhardt, and J.N. Aubertot. 2001. Parameter estimation for crop models: A new approach and application to a corn model. Agron. J. 93:757-766.

Wu, B.H., B. Quilot, J. Kervella, M. Génard, and S.H. Li. 2003. Analysis of genotypic variation of sugar and acid contents in peaches and nectarines through the principal component analysis. Euphytica 132:375-384. 